\title{
Energy Consumption and Economic Growth: New Evidence from the OECD Countries
}

\author{
Giray Gozgor Ph.D. \\ Istanbul Medeniyet University, Istanbul, Turkey \\ E-mail: giray.gozgor@medeniyet.edu.tr \\ Chi Keung Marco Lau, Ph.D. \\ University of Huddersfield, Huddersfield, the United Kingdom \\ E-mail: $\underline{\text { C.Lau@hud.ac.uk }}$ \\ Zhou Lu, Ph.D. \\ School of Economics, Tianjin University of Commerce, China \\ Email: zhoulu949@yahoo.com
}

\begin{abstract}
This paper introduces a growth model that considers the indicator of economic complexity as a measure of capabilities for exporting the high value-added (sophisticated) products. Empirically, the paper analyzes the effects of the renewable and the non-renewable energy consumption on the economic growth in the panel data of 29 Organization for Economic Cooperation and Development (OECD) countries for the period from 1990 to 2013. For this purpose, the paper considers the panel autoregressive distributed lag (ARDL) and the panel quantile regression $(\mathrm{PQR})$ estimations. The paper finds that not only the economic complexity, but also both the non-renewable and the renewable energy consumption are positively associated with a higher rate of economic growth.
\end{abstract}

Keywords: energy consumption; economic growth; energy-growth nexus; economic complexity; panel ARDL model; panel quantile regression

JEL Classification Codes: O13; Q43; C23; C33 


\section{Introduction}

Renewable energy gains significant attention during the last decade. Indeed, renewables have been the fastest growing energy source in the world since the late 2000s (Apergis and Payne, 2012). The main reason for the rise of renewable energy is related to the climate change, one of the leading problems in today's world. Scientists are on the consensus that production of fossil fuel has a significant effect on greenhouse emissions, and this has been the fundamental source of the global warming. In other words, fossil fuel can drive the climate change. Climate change becomes to threaten the sustainable growth (Kaygusuz, 2007); and therefore, policymakers gear up the investments in renewable energy, especially in most developed countries and some developing countries (e.g. Brazil and China). Indeed, effective renewable energy policies can reduce the level of greenhouse emissions and this can decelerate the climate change; i.e. renewable energy can provide the sustainable economic growth. At this stage, some efficient government policies, such as credit and tax benefits, renewable energy portfolio standards, and renewable energy certificates has also promoted the renewables (Apergis and Payne, 2010a). Another reason for the rise of renewable consumption is that the technological improvement, which reduces the total costs of renewable energy installation facilities (Bowden and Payne, 2009). According to Apergis and Payne (2010a and 2010b), the remarkable price volatility in oil markets during the last decade is also a significant factor that leads to the rise of the renewable energy sources.

In the light of these developments, our paper aims to reanalyze the energy-growth in the panel data of 29 OECD countries for the period from 1990 to 2013. For this purpose, it theoretically builds up a new growth model that considers the impact of the economic complexity indicator as a measure of "capabilities" for exporting the high value-added (sophisticated) products. At this point, previous papers have paid regard to the effects of the capital and the labor in the growth models for analyzing the relationship between energy 
consumption and economic growth. This type of empirical modeling can be called as a "traditional" approach and it is mainly considered for addressing the issue of omitted variable bias (e.g. Apergis and Payne, 2010a, 2010b, 2011, and 2012; Payne, 2009). However, the traditional approach is actually based on the neoclassical K-L (Solow-Swan) growth model, which considers the effects of merely the capital and the labor on the economic growth.

However, the empirical growth literature has recently addressed the role of human capital (skills) and institutional quality (the rule of law and property rights) on economic growth. Technological improvement is closely associated with research and development (R\&D) expenditures. It is also important to emphasize that the $R \& D$ expenditures are also one of the leading determinants of economic growth (Stafforte and Tamberi 2012). ${ }^{1}$ Indeed, the technological process is the main source of the economic growth and is closely related to the "capabilities" of an economy (Hidalgo, 2009; Hidalgo and Hausmann, 2009; Hidalgo et al., 2007). Therefore, the production in advanced economies is mainly based on the production of goods and services, which require the skilled labor and a higher level of technology. In the seminal paper, Hidalgo (2011) criticizes the above mentioned "traditional approach" to understand the economic growth process. The traditional approach assumes that there are only two factors (capital and labor) to explain economic growth; however, Hidalgo (2011) indicates that a production process not only depends on capital and labor but also requires "capabilities". According to Hidalgo and Hausmann (2009), "capabilities" consists of physical infrastructure (airports, highways, etc.), human capital (knowledge and skilled labor force), and institutional quality (patent laws, property rights, and the rule of law).

At this point, the capabilities of a country can be measured by the Economic Complexity Indicator (henceforth ECI) (Hausmann et al., 2011). The ECI is firstly introduced by Hidalgo and Hausmann (2009). The ECI is constructed from international trade data from

\footnotetext{
${ }^{1}$ Technological improvement can be defined a process that reduces production costs or causes the emergence of new products.
} 
the COMTRADE database of the United Nations (UN) and the indicator considers the exporting goods; i.e. not all goods produced in a country. A higher value of the ECI indicates a higher level (sophisticated) capabilities of a country in the production process, especially in the manufacturing. Therefore, the ECI reflects the production characteristics, i.e. capabilities of a country (Hausmann et al., 2011). ${ }^{2}$ In short, the ECI is also a measure of sophisticated and skilled-based labor production of a country as well as it captures the knowledge on the production of a country to achieve the desired (efficient) level of gross domestic product (GDP) (Hidalgo et al., 2007; Hidalgo and Hausmann, 2009). In short, the ECI is closely related to the sustainable growth. ${ }^{3}$

In this paper, we propose a new approach to explain the economic growth process. In our empirical model, GDP per employed person is determined by the ECI and the primary energy consumption. Following Apergis and Payne (2012), we also divide the total energy consumption as the renewable- and the non-renewable energy consumption. At this stage, we empirically test the validity of our "new approach" for the economic growth and focus on 29 OECD countries for the period from 1990 to 2013. According to the dataset of Hausmann et al. (2011), the OECD countries are the highest level of the economic complexity and this could be the main driver of the economic growth. In other words, a higher industrialization and capabilities of an economy can lead to a higher level of economic growth in the OECD countries. However, achieving higher levels of economic complexity can also require a higher level of energy consumption. To test this hypothesis, that is, whether energy consumption and economic complexity lead to a higher economic growth, we run the panel autoregressive distributed lag and the panel quantile regression estimations.

\footnotetext{
${ }^{2}$ Furthermore, Felipe et al. (2012) observe the positive effect of economic complexity indicator on economic development. Hartmann et al. (2017) also find the suppressing effect of economic complexity on the income inequality.

${ }^{3}$ For the details of the ECI, visit https://atlas.media.mit.edu/en/.
} 
To the best of our knowledge, our paper is the first in the literature to analyze the impacts of economic complexity as well as the renewable- and the non-renewable energy consumption within the context of "new" growth fundamentals. The context of "new" growth fundamentals are measured by the economic complexity indicator. The results of our paper demonstrate that not only the economic complexity but also the non-renewable and the renewable energy consumption are positively associated with a higher rate of economic growth in 29 OECD countries for the period from 1990 to 2013.

The rest of the paper is organized as follows. Section 2 briefly reviews the previous literature on the relationship between the energy consumption and the economic growth. Section 3 introduces the empirical model and the data as well as it explains the econometric methodology. Section 4 reports the empirical findings. Section 5 concludes the paper by discussing the findings and the policy implications.

\section{Literature Review}

There are four hypotheses about the causality for the energy-growth nexus. First is the "growth hypothesis" and it indicates that the energy consumption causes to the economic growth. Second is the "conservation hypothesis", which proposed that the growth causes to the energy consumption. Third, is the "feedback hypothesis", and it suggests a bidirectional causality between the energy consumption and the growth. Finally, the "neutrality hypothesis" implies that there is no statistically significant causality between the growth and the energy consumption. Indeed, many papers empirically analyze the relationship between the energy consumption and the economic growth in different countries and regions by different datasets. These papers also consider different econometric methods; and therefore, the empirical results are miscellaneous. For example, the recent literature survey of Adewuyi and Awodumia (2017) reviews 136 papers, which are published in the last three decades and 
the paper concludes that $41 \%$ of them obtain validity of the feedback effect, $25 \%$ of them conclude validity of the growth hypothesis, $21 \%$ of them propose the validity of the conservation hypothesis, and $13 \%$ of them find the validity of the neutrality hypothesis in the energy-growth nexus.

The energy consumption-economic growth nexus has been widely investigated; however, the papers focus on the effects of both the non-renewable- and the renewable energy consumption on economic growth are still limited. ${ }^{4}$ For instance, considering the panel ECM, Apergis and Payne (2012) demonstrate a bidirectional causality between the renewable energy and the economic growth as well as the non-renewable energy and the economic growth in 80 countries over the period 1990-2007. Using the ordinary least squares (OLS), the dynamic ordinary least squares (DOLS), and the fully-modified ordinary least squares (FMOLS) estimations, Jebli and Youssef (2015) find the validity of growth hypothesis for both the relationship from the renewable and the non-renewable energy consumption to the economic growth in 69 countries over the period 1980-2010. Using the panel data estimation techniques that capture the cross-sectional dependence and the heterogeneity, Bhattacharya et al. (2016) examine the impacts of energy consumption on the economic growth in 38 countries for the period from 1991 to 2012. Recently Shahbaz, Sarwar, Chen, and Malik (2017) examine the dynamic relationship between the electricity consumption, the oil price, and the GDP in 157 countries and they conclude that developing countries rely heavily on the electricity consumption in providing the economic growth. Shahbaz, Hoang, Mahalik, and Roubaud (2017) also analyze the asymmetric relationship between the energy consumption and the economic growth and the paper shows that the negative shocks of energy consumption have only the significant impact on the economic growth. According those previous papers, the non-renewable energy consumption is

\footnotetext{
${ }^{4}$ See the literature reviews of Adewuyi and Awodumia (2017), Ozturk (2010), and Tiba and Omri, (2017).
} 
positively related to the economic growth in most of the countries, but there is no significant relationship in the most of the cases for the renewable energy-growth nexus.

There are also panel data studies for analyzing the relationship between the renewable energy consumption and the economic growth. Using a panel cointegration test, Sadorsky (2009a) finds the significant causality that runs from the renewable energy to the economic growth in the G7 countries for the period from 1980 to 2005. Similarly, Sadorsky (2009b) runs the panel error correction model (ECM) and observes the causal relationship that runs from the growth to the renewable energy consumption in 18 emerging countries over the period 1994-2003. Salim and Rafiq (2012) use the Granger causality test and find that there is a bidirectional causality between the renewable energy and the economic growth in six emerging economies from 1980 to 2006 in the short-run. However, a different finding is obtained for the long-run that is the significant causal relationship that runs from the economic growth to the renewable energy. Apergis and Payne (2010a) focus on the panel dataset of 20 OECD countries for the period from 1985 to 2005 . The empirical results from the vector error correction model (VECM) and the Granger causality test show that there is the bidirectional causal relationship between the renewable energy and the economic growth. A similar finding of bidirectional causality between the related two variables is obtained by Apergis and Payne (2010b) and their empirical analysis is based on the panel dataset of 13 Eurasian countries over the period 1992-2007. Using the FMOLS estimations, Apergis and Payne (2011) also conclude that there is the bidirectional causality between the renewable energy consumption and the economic growth in six Central America countries for the period from 1980 to 2006. Considering the FMOLS estimations, Al-Mulali et al. (2013) examine the renewable energy-growth nexus in 108 countries for the period from 1980 to 2009 and they find that there is the bidirectional causality between the renewable energy and the economic growth in 85 of 108 countries. Using the FMOLS and the panel smooth transition VECM 
estimations, Apergis and Payne (2014) observe that the bidirectional causality between the renewable energy and the economic growth in seven Central American countries from 1980 to 2010. Using the ARDL model, Sebri and Ben-Salha (2014) find the bidirectional causal relationship between the renewable energy and the economic growth in BRICS countries from 1971 to 2010. Using the heterogeneous panel Granger causality test, Chang et al. (2015) also find the bidirectional causality between the renewable energy and the economic growth in the G7 countries from 1990 to 2011 . Using the K-L model and the Toda-Yamamoto causality test procedure, Yildirim and Aslan (2012) investigate the validity of energy-growth nexus in 17 OECD countries. The paper only finds the causal relationship from the energy consumption to the economic growth only in Japan. A bidirectional causality is obtained in Italy, New Zealand, Norway, and Spain. Besides, there is the significant causality from the economic growth to the energy consumption in Australia, Canada, and Ireland. Furthermore, using the random-effect model, Menegaki (2011) finds that there is no significant causal relationship between the renewable energy consumption and the economic growth in 27 European countries over the period 1997-2007. Using the OLS estimations, Abanda et al. (2012) find no significant causality in the renewable energy-growth nexus in African countries. Using the ECM and the Granger causality test procedures, Aïssa et al. (2014) also observe that there is no significant causal relationship between the renewable energy and the economic growth in 11 African countries for the period from 1980 to 2008.

Some papers have considered the $R \& D$ expenditures or the human capital in the empirical growth model. For instance, Fang and Chang (2016) consider the K-L model (augmented production function) in the energy-growth nexus and their paper is the first to include the human capital into the empirical model. Using the panel unit root and the panel cointegration tests that capture the effects of cross-sectional dependence, they find that the economic growth causes to the energy consumption in the panel dataset of 16 Asia Pacific 
countries over the period 1970-2011. For example, using the OLS estimations, Fang (2011) observes that there is the significant causal relationship that runs from the renewable energy to the economic growth in China for the period from 1978 to 2008. The empirical model in Fang (2011) uses the R\&D expenditures to capture the technological progress. Following Fang (2011), Inglesi-Lotz (2016) also includes the R\&D expenditures into the K-L model. Using the Pedroni's panel cointegration test, Inglesi-Lotz (2016) examines the effects of the renewable energy consumption on the economic growth in the panel data of 34 OECD countries for the period from 1990 to 2010 . The paper finds the significant causality that runs from the renewable energy consumption to the economic growth.

To conclude the literature review, the mixed results from the renewable energygrowth nexus are observed in the previous literature. Specifically, the mixed results are obtained by Tugcu et al. (2012) in the G7 countries; by Pao et al. (2014) in the MIST countries; by Lin and Moubarak (2014) in China; by Carmona et al. (2017) in the U.S; by Solarin and Ozturk, (2015) in the Latin American countries. The mixed findings are due to the different choices of empirical growth model and the country samples or the econometric methodology. Using the economic complexity indicator instead of the capital and the labor, our paper offers a different approach. At this stage, we do not claim that our empirical model is better. We attempt to justify that there would be a different approach to enhance our knowledge on the growth-energy nexus. We demonstrate that our new approach fits well with the panel data of 29 OECD countries.

\section{Data, Empirical Model, and Methodology}

\subsection{Data and Empirical Model}

The previous literature on energy-growth nexus is based on a "traditional" growth model, known as the K-L model (e.g. Apergis and Payne 2010a, 2010b, 2011, and 2012.) In the K-L 
model, income (GDP), which is represented by $Y$ is a function of two factors: capital $(K)$ and labor $(L)$. This model can be represented by the following formulae:

Y

$$
=
$$

f

$(\mathrm{K}$,

L)

(1)

If we divide the equation with $L$ then we can obtain the following:

$\mathrm{Y} / \mathrm{L}$

$$
=\quad \mathrm{f}
$$

(2)

By adding the renewable energy (RE) and the non-renewable energy consumption

(NRE) into the growth model in Eq. (2), we can obtain the following: ${ }^{5}$

$$
\begin{array}{lllll}
\mathrm{Y} / \mathrm{L} & \mathrm{f} & (\mathrm{K} / \mathrm{L}, & \mathrm{RE}, & \mathrm{NRE})
\end{array}
$$

What we basically do to replace the (K/L) with the economic complexity indicator $(\mathrm{ECI})$, since it is also a measure of the productivity and the economic structure $(\mathrm{K} / \mathrm{L})$; and then, our growth model will be written as follows:

$$
\begin{array}{lllll}
\mathrm{Y} / \mathrm{L} & \mathrm{f} & (\mathrm{ECI}, & \mathrm{RE}, & \mathrm{NRE})
\end{array}
$$

The empirical model in Eq. (4) considers the ECI and the renewable- and the nonrenewable energy consumption and provides the baseline evidence on the role of the ECI in the energy-growth nexus for a panel of 29 countries: Australia, Austria, Belgium, Canada, Chile, the Czech Republic, Denmark, Finland, France, Germany, Greece, Hungary, Ireland, Israel, Italy, Japan, the Netherlands, New Zealand, Norway, Poland, Portugal, Slovakia, South Korea, Spain, Sweden, Switzerland, Turkey, the United Kingdom (UK), and the United States (U.S.). The data cover the time spanning from 1990 to 2013. The selection of the

\footnotetext{
${ }^{5}$ Instead of the total (overall) primary energy consumption, we aim to see there could be potentially different effects of the non-renewable and the renewable energy consumption on the economic growth. Doing so, we also attempt to link with the broader literature by including the renewable energy consumption.
} 
countries and the period is based on the availability of the data. Our baseline modeling framework is given as follows in general notation:

$$
(Y / L)_{i t}=f\left(E C I_{i t}^{\alpha_{1}}, R E_{i t}^{\alpha_{2}}, N R E_{i t}^{\alpha_{3}}\right)
$$

The empirical model in Eq. (5) is defined in logarithmic form as follows: ${ }^{6}$

$$
\log (Y / L)_{i t}=\alpha_{0}+\alpha_{1} E C I_{i t}+\alpha_{2} \log R E_{i t}+\alpha_{3} \log N R E_{i t}+\varepsilon_{t}
$$

Where, $Y / L_{i t}$ denotes the real GDP in billions of constant 2005 U.S. Dollars per engaged labor (employment); $\mathrm{RE}_{\mathrm{it}}$ is the total renewable energy consumption defined in million tonnes oil equivalent; $\mathrm{NRE}_{\mathrm{it}}$ is the total non-renewable energy consumption defined in million tonnes oil equivalent; and $\mathrm{ECI}_{\mathrm{it}}$ is the economic complexity indicator (ECI), which measures how a country can produce and export a complex product. In other words, if a country has a higher level of economic structure, it can be able to produce and to export complex (higher value-added) products.

The real GDP and the total labor force data are obtained from the World Development Indicators (WDI) of the World Bank. The total renewable and the non-renewable energy consumption come from the Statistical Review of World Energy of the British Petroleum (BP) (2016 version). The economic complexity indicators are obtained from the Atlas of the Economic Complexity of Hausmann et al. (2011). A summary of descriptive statistics is reported in Appendix Table I and the graphs of the variables are provided in Appendix Figure I. At this stage, we expect that the ECI, the renewable energy consumption, and the nonrenewable energy consumption are positively related to the economic growth.

\subsection{Econometric Methodology}

To test the validity of our new economic growth approach, which is introduced in the previous subsection, we use the panel ARDL and the PQR estimations.

\footnotetext{
${ }^{6}$ We did not use the natural logarithmic of the economic complexity indicator since there are the negative values in the dataset.
} 


\subsubsection{Panel Autoregressive Distributed Lag (ARDL) Model}

Due to the possibility of the mixed nature of stationary for variables of interest, we employ the panel ARDL model with the country fixed-effect and the period fixed-effect, as proposed by Pesaran et al. (1999). Another advantage of the panel ARDL test is that it allows the nonlinear relationship between the GDP per employed person, the total renewable energy consumption (RE), the total non-renewable energy consumption (NRE), and the economic complexity indicator (ECI). The model is specified as follows:

$$
\begin{gathered}
\Delta \frac{\ln Y}{L}_{i t}=\lambda_{0+} \sum_{i=1}^{m} \lambda_{1 i} \Delta \frac{\ln Y}{L}_{i t-1}+\sum_{i=1}^{m} \lambda_{2 i} \Delta \ln R E_{i t-1}+\sum_{i=1}^{m} \lambda_{3 i} \Delta \ln N R E_{i t-1}+ \\
\sum_{i=1}^{m} \lambda_{4 i} \Delta E C I_{i t-1}+\lambda_{5} \frac{\ln Y}{L}_{i t-1}+\lambda_{6} R E_{i t-1}+\lambda_{7} \ln N R E_{i t-1}+\lambda_{8} E C I_{i t-1}+v_{i t}
\end{gathered}
$$

where $m$ is the lag order and $v_{t}$ is assumed to be an independent and identically distributed error term. Eq. (7) can be transformed into an error correction model (ECM) yielding:

$$
\begin{gathered}
\Delta \frac{\ln Y}{L}_{i t}=\lambda_{0+} \sum_{i=1}^{m} \lambda_{1 i} \Delta \frac{\ln Y}{L}_{i t-1}+\sum_{i=1}^{m} \lambda_{2 i} \Delta \ln R E_{i t-1}+\sum_{i=1}^{m} \lambda_{3 i} \Delta \ln N R E_{i t-1}+ \\
\left.\sum_{i=1}^{m} \lambda_{4 i} \Delta E C I_{i t-1}+\xi \frac{\ln Y}{L}_{i t-1}+\beta_{1} R E_{t i-1}+\beta_{2} \ln N R E_{i t-1}+\beta_{3} E C I_{i t-1}\right)+\mu_{i t}
\end{gathered}
$$

where $\xi$ is the speed of adjustment parameter. $\beta_{1}$ and $\beta_{2}$, and $\beta_{3}$ are the long-run coefficients for the RE, the NRE, and the ECI respectively. The short-run parameters are represented by $\sigma_{1 i}, \sigma_{2 i}, \sigma_{3 i}$, and $\sigma_{4 i}$. Therefore, the panel ARDL (p, q, k, g) model yields:

$$
\begin{gathered}
\Delta \ln \frac{\ln Y}{L}_{i t}= \\
\sigma_{0+} \sum_{i=1}^{p} \Delta \sigma_{1 i} \Delta \ln \frac{\ln Y}{L}_{i t-p}+\sum_{i=1}^{q} \Delta \sigma_{2 i} \Delta \ln R E_{i t-q}+\sum_{i=1}^{k} \Delta \sigma_{3 i} \Delta \ln N R E_{i t-k}+ \\
\sum_{i=1}^{g} \Delta \sigma_{4 i} \Delta E C I_{i t-g}+\xi\left(\ln \frac{\ln Y}{L}_{i t-1}+\beta_{1} \ln R E_{t i-1}+\beta_{2} \ln N R E_{i t-1}+\beta_{3} E C I_{i t-1}\right)+\mu_{i t}
\end{gathered}
$$


The methodology used the ARDL model is to address these variables in the short run and the long run co-integrated variables, jointly. This method has advantages over other conventional multivariate methods of the cointegration. ${ }^{7}$

\subsubsection{Panel Quantile Regression (PQR)}

In this section, we conduct the PQR methodology as a robustness test and estimate the parameters at different points on the (conditional) output per labor (i.e. the economic growth). The main advantage of using the PQR is that it can minimize the biases raised from outliers, and the PQR estimator is more efficient than OLS estimators when error terms are not normally distributed. More importantly, the effects of the renewable energy consumption, the economic complexity indicator, and the non-renewable energy consumption may be different for a country at the different productivity levels. Given a set of independent variables $\mathrm{X}_{\mathrm{it}}$, we can write $\tau$ th quantile $(0<\tau<1)$ as the conditional distribution of the dependent variable (i.e. the log of real GDP per labor), such that:

$$
Q_{\tau}\left(\frac{\operatorname{Ln}\left(\frac{Y}{L}\right)_{i t}}{X_{i t}}\right)=\alpha_{\tau}+\beta_{\tau} X_{i t}+\alpha_{\tau} \mu_{i t}
$$

In Eq. (10), $\mathrm{Ln}(\mathrm{Y} / \mathrm{L})_{\mathrm{it}}$ is the $\log$ of real GDP per labor of county $i$ at time $t$ and $\mathrm{X}_{\mathrm{it}}$ represents the vector of three independent variables; i.e. the non-renewable energy consumption ( $\left.\operatorname{LnNRE}_{\mathrm{it}}\right)$, the renewable energy consumption $\left(\mathrm{LnRE}_{\mathrm{it}}\right)$, and the economic complexity indicator (ECI). $\mathrm{u}_{\mathrm{it}}$ denotes unobservable factors, such as the institutional quality. The parameters in Eq. (10) are estimated by minimizing the absolute value of the residuals, using the following objective function:

\footnotetext{
${ }^{7}$ At this stage, the panel ARDL estimations used in our paper take also the effects of the structural changes into account as the robustness check. The results are similar to the benchmark estimations; and therefore, we did not report the results to save space.
} 


$$
\begin{aligned}
& Q_{\tau}\left(\beta_{\tau}\right)=\min _{\beta} \sum_{i=1}^{n}\left[\left|\operatorname{Ln}\left(\frac{Y}{L}\right)_{i t}-\beta_{\tau} X_{i t}\right|\right]=\min _{\beta}\left[\sum_{i: \operatorname{Ln}\left(\frac{Y}{L}\right)_{i t} \geq \beta X_{i}} \tau\left|\operatorname{Ln}\left(\frac{Y}{L}\right)_{i t}-\beta_{\tau} X_{i t}\right|+\right. \\
& \left.\sum_{i: \operatorname{Ln}\left(\frac{Y}{L}\right)_{i t}^{n}<\beta X_{i t}}(1-\tau)\left|\operatorname{Ln}\left(\frac{Y}{L}\right)_{i t}-\beta_{\tau} X_{i t}\right|\right],
\end{aligned}
$$

At this stage, Koenker (2004) suggests using the shrinkage methodology to estimate a vector of the fixed-effects and Canay (2011) introduces a two-step methodology of estimating panel quantile regression models with the fixed-effects. We use the PQR estimations of Canay (2011) in the empirical estimations.

\section{Empirical Findings}

Table 1 reports the degree of integration and the stationary properties of the respective variables. We first use the panel ADF (LLC) test proposed by Levin et al. (2002) by assuming the homogeneity in the dynamics of the autoregressive coefficients for all panel units. In addition, we use the nonparametric tests of Maddala and Wu (1999) including the Fisher-ADF and the Fisher-PP tests, take into account of the heterogeneity across units. Finally, we consider the cross-sectional dependence unit root (CIPS) test of Pesaran (2007). The panel unit root tests indicate that ECI and lnNRE is stationary; while, $\operatorname{lnRE}$ and $\ln \mathrm{Y} / \mathrm{L}$ are ambiguous and possibly integrated of order one.

[Insert Table 1 about here]

Table 2 presents the results for Equations (7) and (8); the error-correction coefficient $(-0.061)$ was found to be negative and statistically significant at the $1 \%$ level, indicating that the adjustment speed is about $6.1 \%$. Table 2 also displays the long-run parameter estimates based on the panel ARDL. The coefficients are positive and statistically significant at the $1 \%$ level for the non-renewable energy consumption, the renewable energy consumption, and the economic complexity indicator, but the coefficient is only significant at the $10 \%$ level for the 
renewable energy consumption. Since energy consumption variables are expressed in natural logarithms, the parameter estimates of the model can be interpreted as elasticity estimates. The results indicate that a $1 \%$ increase in non-renewable energy consumption increases real GDP per labor by $1.08 \%$; a $1 \%$ increase in renewable energy consumption increases real GDP per labor by $0.40 \%$, and a $1 \%$ increase in economic complexity increases real GDP per labor by $1.27 \%$. Table 2 also shows the results from the panel error correction model, and it indicates that the renewable energy consumption, the non-renewable energy consumption, and the economic complexity index have the positive impact on productivity $(\mathrm{Y} / \mathrm{L})$ in the short-run.

\section{[Insert Table 2 about here]}

The empirical findings from the PQR approach of Canay (2011) are reported in Table 3 ; we can see all estimates are positive and significant at the $1 \%$ level, except the coefficient of the renewable energy consumption at the high quantile of productivity (i.e. $\tau=0.9$ ). More interestingly, the marginal effects of the economic complexity indicator on the productivity are higher at the higher quantiles of productivity. However, we do not observe the system effects of the non-renewable and the renewable energy consumption on the GDP per employed person at the high quantile of GDP per employed person.

[Insert Table 3 about here]

The main policy implication of the estimation results of the PQR model is that there is a significant heterogeneity across the OECD countries for the effects of the renewable energy on the economic growth process. The results are differentiated at the high quantile of the GDP per labor since the higher income countries can provide more sources for enhancing renewable energy. Since the renewable energy investments require a long-term funding and they are the expensive investment, income level can be the main reason (mechanism) that differentiation of the findings from the PQR. Therefore, policymakers should consider the 
role of the economic complexity and renewable energy sources to provide the sustainable economic growth.

The result of the positive effect both of the renewable- and the non-renewable energy consumption on economic growth suggest the validity of the growth hypothesis and this result is also parallel with the previous results of Jebli and Youssef (2015) for 69 countries. The results for the validity of the growth hypothesis for the non-renewable energy-growth nexus are in line with the findings of Bhattacharya et al. (2016). The findings of the validity of the growth hypothesis in renewable energy-growth nexus are in line with the findings of Inglesi-Lotz (2016) and Sadorsky (2009a) in the panel data sets of 34 OECD and the G7 countries, respectively.

\section{Conclusion}

In this paper, we analyzed the effects of the renewable- and the non-renewable energy consumption on the economic growth in 29 OECD countries. To this end, we introduced the growth model that captures the effects of the economic complexity indicator as the measure of capabilities and productivity for exporting the high value-added (sophisticated) products. Empirically, we tested the validity of our growth model in the panel dataset of 29 OECD countries for the period from 1990 to 2013. For this purpose, we run the panel unit root tests of well as the panel ARDL and the PQR estimations. To the best of our knowledge, our paper is the first paper that controls the effects of the economic complexity on the energy-growth nexus. We found the positive impact of the economic complexity on the economic growth and there is the positive effects of both the renewable- and the non-renewable energy consumption on the economic growth. The findings from the PQR estimations also indicate the heterogeneity across countries in the role of the renewable energy in affecting the 
economic growth. In short, our results are robust for implementing different econometric techniques.

We observed that both the renewable- and the non-renewable energy consumption positively affect the economic growth and this means that both types of energy sources are crucial for the economic growth. At this point, it is important to note that the difference between the related energy sources is based on the carbon emissions. The renewable energy consumption can decrease the level of carbon emissions. As indicated by Kaygusuz (2007) and Apergis and Payne (2010a, 2010b, 2011, and 2012), the rise of the renewable energy meets the sustainable growth since it can decelerate the climate change. Renewable energy is related to the technological change. Therefore, the rise of the renewable energy can also help to upgrade the complexity of exports basket and this can also positively affect the economic growth. In addition, according to Bhattacharya et al. (2016), investments in renewable energy projects can enhance renewable energy consumption and this can promote the economic growth as well as decrease environmental degradation. To put it differently, the benefit of renewable energy for decelerating climate change is also in line with the sustainable growth objectives. At this point, our findings imply that policymakers should not only focus on the rise of renewable energy but also on the non-renewable energy to support the economic growth.

The novelty of our paper is that to construct the theoretical model to link the economic complexity between the energy-growth nexus. We can suggest that our theoretical model will be suitable to analyze the energy-growth nexus when we consider the state-of-artof the growth models. Economic complexity can capture the effects of human capital and institutions on the economic growth. Therefore, policymakers should consider the role of the economic complexity to provide the sustainable economic growth. 
It is important to note that our empirical model assumes that energy causes (or not) economic growth; and not vice versa or both simultaneously. Despite nothing wrong with this assumption (all models make their own assumptions), we cannot examine the relationship in each country. Therefore, a future paper can analyze the dynamic effects of economic complexity on the energy-growth nexus in other countries. In here, a future paper can use the nonlinear models and the time-series analysis to analyze the case of each county.

Finally, our paper includes the non-renewable- and the renewable energy consumption at the aggregated level for investigating the impact of the economic complexity indicator on the economic growth. Therefore, a future paper can focus on the renewable energy consumption at the disaggregated level (e.g. the biomass, the geothermal, the solar, and the wind) and the non-renewable energy consumption (e.g. coal, oil, natural gas, and nuclear) in the energy-growth nexus by using the economic complexity indicator.

\section{References}

Abanda FH, Ng'ombe A, Keivani R, Tah JHM. The link between renewable energy production and gross domestic product in Africa: A comparative study between 1980 and 2008. Renewable and Sustainable Energy Reviews 2012; 16 (4): 2147-53.

Adewuyi AO, Awodumi OB. Renewable and non-renewable energy-growth-emissions linkages: Review of emerging trends with policy implications. Renewable and Sustainable Energy Reviews 2017; 69: 275-91.

Aissa MSB, Jebli MB, Youssef SB. Output, renewable energy consumption and trade in Africa. Energy Policy 2014; 66: 11-8.

Al-Mulali U, Fereidouni HG, Lee JY, Sab CN. Examining the bi-directional long run relationship between renewable energy consumption and GDP growth. Renewable and Sustainable Energy Reviews 2013; 22: 209-22. 
Apergis N, Payne JE. Renewable and non-renewable energy consumption-growth nexus: Evidence from a panel error correction model. Energy Economics 2012; 34 (3): 7338.

Apergis N, Payne JE. Renewable energy consumption and economic growth: Evidence from a panel of OECD countries. Energy Policy 2010a; 38 (1): 656-60.

Apergis N, Payne JE. Renewable energy consumption and growth in Eurasia. Energy Economics 2010b; 32 (6): 1392-7.

Apergis N, Payne JE. Renewable energy, output, CO2 emission and fossil fuel prices in Central America: Evidence from a non-linear panel smooth transition vector error correction model. Energy Economics 2014; 42: 226-32.

Apergis N, Payne JE. The renewable energy consumption-growth nexus in Central America. Applied Energy 2011; 88 (1): 343-7.

Bhattacharya M, Paramati RS, Ozturk I, Bhattacharya S. The effect of renewable energy consumption on economic growth: Evidence from top 38 countries. Applied Energy 2016; 162: 733-41.

Bowden N, Payne JE. The causal relationship between U.S. energy consumption and real output: A disaggregated analysis. Journal of Policy Modeling 2009; 31 (2): 180-8.

Canay IA. A simple approach to quantile regression for panel data. Econometrics Journal $2011 ; 14$ (3): 368-86.

Carmona M, Congregado E, Feria J, Iglesias J. The energy-growth nexus reconsidered: Persistence and causality. Renewable and Sustainable Energy Reviews 2017; 71: $342-7$.

Chang T, Gupta R, Inglesi-Lotz R, Simo-Kengne B, Smithers D, Trembling A. Renewable energy and growth: Evidence from heterogeneous panel of G7 countries using Granger causality. Renewable and Sustainable Energy Reviews 2015; 52: 1405-12. 
Fang Y. Economic welfare impacts from renewable energy consumption: The China experience. Renewable and Sustainable Energy Reviews 2011; 15 (9): 5120-8.

Fang Z, Chang Y. Energy, human capital and economic growth in Asia Pacific countries Evidence from a panel cointegration and causality analysis. Energy Economics 2016; 56: $177-84$.

Felipe J, Kumar U, Abdon A, Bacate M. Product complexity and economic development. Structural Change and Economic Dynamics 2012; 23 (1): 36-68.

Hartmann D, Guevara MR, Jara-Figueroa C, Aristarán M, Hidalgo CA. Linking economic complexity, institutions, and income inequality. World Development 2017; 93: 75-93.

Hausmann R, Hidalgo CA, Bustos S, Coscia M, Chung S, Jimenez J, Simoes A, Yildirim M. The Atlas of Economic Complexity 2011; Puritan Press: Cambridge, MA.

Hidalgo CA, Hausmann R. The building of economic complexity. Proceedings of the National Academy of Sciences of the United States of America (PNAS) 2009; 106 (26): 10570-5.

Hidalgo CA, Klinger B, Barabasi AL, Hausmann R. The product space conditions the development of nations. Science 2007; 317 (5837): 482-7.

Hidalgo CA. Discovering Southern and East Africa's Industrial Opportunities. The German Marshall Fund of the United States 2011; Economic Paper Series: Washington, D.C.

Hidalgo CA. The dynamics of economic complexity and the product space over a 42 year period. Harvard University CID Working Paper 2009; No.189.

Inglesi-Lotz R. The impact of renewable energy consumption to economic growth: A panel data application. Energy Economics 2016; 53: 58-63.

Jebli MB, Youssef SB. Output, renewable and non-renewable energy consumption and international trade: Evidence from a panel of 69 countries. Renewable Energy 2015; 83: 799-808. 
Kaygusuz K. Energy for sustainable development: Key issues and challenges. Energy Sources, Part B: Economics, Planning, and Policy 2007; 2 (1): 73-83.

Koenker R. Quantile regression for longitudinal data. Journal of Multivariate Analysis 2004; 91 (1): 74-89.

Levin A, Lin CF, Chu C. Unit root tests in panel data: Asymptotic and finite-sample properties. Journal of Econometrics 2002; 108 (1): 1-24.

Lin B, Moubarak M. Renewable energy consumption - economic growth nexus for China. Renewable and Sustainable Energy Reviews 2014; 40: 111-7.

Maddala GS, Wu S. A comparative study of unit root tests with panel data and a new simple test. Oxford Bulletin of Economics and Statistics 1999; 61: 631-52.

Menegaki AN. Growth and renewable energy in Europe: A random effect model with evidence for neutrality hypothesis. Energy Economics 2011; 33 (2): 257-63.

Ozturk I. A literature survey on energy-growth nexus. Energy Policy 2010; 38 (1): 340-9.

Pao H-T, Li Y-Y, Fu H-C. Clean energy, non-clean energy, and economic growth in the MIST countries. Energy Policy 2014; 67: 932-42.

Pesaran MH, Shin Y, Smith RP. Pooled mean group estimation of dynamic heterogeneous panels. Journal of the American Statistical Association 1999; 94 (446): 621-34.

Pesaran MH. A simple panel unit root test in the presence of cross-section dependence. Journal of Applied Econometrics 2007; 22 (2): 265-312.

Sadorsky P. Renewable energy consumption and income in emerging economies. Energy Policy 2009b; 37 (10): 4021-8.

Sadorsky P. Renewable energy consumption, CO2 emissions and oil prices in the G7 countries. Energy Economics 2009a; 31 (3): 456-62.

Salim RA, Rafiq S. Why do some emerging economies proactively accelerate the adoption of renewable energy? Energy Economics 2012; 34 (4): 1051-7. 
Sebri M, Ben-Salha O. On the causal dynamics between economic growth, renewable energy consumption, $\mathrm{CO}_{2}$ emissions and trade openness: Fresh evidence from BRICS Countries. Renewable and Sustainable Energy Reviews 2014; 39: 14-23.

Shahbaz, M., Sarwar, S., Chen, W., \& Malik, M. N. (2017). Dynamics of electricity consumption, oil price and economic growth: Global perspective. Energy Policy 2017; 108: 256-270.

Shahbaz, M., Van Hoang, T. H., Mahalik, M. K., \& Roubaud, D. (2017). Energy consumption, financial development and economic growth in India: New evidence from a nonlinear and asymmetric analysis. Energy Economics 2017; 63: 199-212.

Solarin SA, Ozturk I. On the causal dynamics between hydroelectricity consumption and economic growth in Latin America countries. Renewable and Sustainable Energy Reviews 2015; 52: 1857-68.

Stafforte S, Tamberi M. Italy in the space (of products). Economia Marche Journal of Applied Economics 2012; 31 (1): 90-113.

Tiba S, Omri A. Literature survey on the relationships between energy, environment and economic growth. Renewable and Sustainable Energy Reviews 2017; 69: 1129-46.

Tugcu CT, Ozturk I, Aslan A. Renewable and non-renewable energy consumption and economic growth relationship revisited: Evidence from G7 countries. Energy Economics 2012; 34 (6): 1942-50.

Yildirim E, Aslan A. Energy consumption and economic growth nexus for 17 highly developed OECD countries: Further evidence based on bootstrap-corrected Grangercausality tests. Energy Policy 2012; 51: 985-93. 
Table 1

Results of the Panel Unit Root Tests

\begin{tabular}{cccc|c}
\hline Variables & LLC & Fisher-ADF & Fisher-PP & CIPS \\
\hline $\mathrm{Y}$ & $-5.08 * * *$ & 55.44 & $83.91 * * *$ & -2.28 \\
$\Delta \mathrm{Y}$ & $-14.39 * * *$ & $278.14 * * *$ & $294.37 * * *$ & $-3.97 * * *$ \\
$\mathrm{RE}$ & $-1.86 * * *$ & $95.94 * * *$ & 35.89 & -2.26 \\
$\Delta \mathrm{RE}$ & $-13.67 * * *$ & $267.09 * * *$ & $257.32 * * *$ & $-3.89 * * *$ \\
$\mathrm{NRE}$ & $-7.89 * * *$ & $117.69 * * *$ & $148.21 * * *$ & $-2.95 * * *$ \\
$\Delta \mathrm{NRE}$ & $15.049 * * *$ & $316.56 * * *$ & $564.71 * * *$ & $-4.95 * * *$ \\
$\mathrm{ECI}$ & $-3.69 * * *$ & $99.95 * * *$ & $103.49 * * *$ & $-2.81 * *$ \\
$\Delta \mathrm{ECI}$ & $-20.61 * * *$ & $360.63 * * *$ & $897.69 * * *$ & $-5.24 * * *$ \\
\hline
\end{tabular}

Notes: $* * * \mathrm{p}<0.01$ and $* * \mathrm{p}<0.05$. The number of lag is based on the Akaike Information Criteria (AIC). Maximum number of lag is 3. 
Table 2

Results of the Panel ARDL Estimations

\begin{tabular}{ccccc}
\hline Variables & Coefficients & Standard Errors & t-Statistics & Probability \\
\hline \multicolumn{5}{c}{ Long Run Equation } \\
\hline LNNONRENE & $1.0839 * * *$ & 0.1587 & 6.8298 & 0.0000 \\
LNRENE & $0.4021 * * *$ & 0.0699 & 5.7507 & 0.0000 \\
ECI & $1.2683 * * *$ & 0.2182 & 5.8136 & 0.0000 \\
\hline \multicolumn{5}{c}{ Short Run Equation } \\
\hline COINTEQ01 & $-0.0609 * *$ & 0.0252 & -2.4211 & 0.0162 \\
D(LNNONRENE) & $0.2357 * * *$ & 0.0662 & 3.5610 & 0.0004 \\
D(LNNONRENE(-1)) & 0.0533 & 0.0717 & 0.7431 & 0.4581 \\
D(LNNONRENE(-2)) & -0.0108 & 0.0785 & -0.1377 & 0.8906 \\
D(LNNONRENE(-3)) & 0.0033 & 0.0591 & 0.0550 & 0.9562 \\
D(LNRENE) & 0.0282 & 0.0213 & 1.3232 & 0.1869 \\
D(LNRENE(-1)) & 0.0078 & 0.0167 & 0.4656 & 0.6419 \\
D(LNRENE(-2)) & 0.0029 & 0.0173 & 0.1662 & 0.8681 \\
D(LNRENE(-3)) & 0.0045 & 0.0108 & 0.4169 & 0.6771 \\
D(ECI) & 0.0074 & 0.0337 & 0.2193 & 0.8266 \\
D(ECI(-1)) & 0.0279 & 0.0338 & 0.8255 & 0.4099 \\
D(ECI(-2)) & 0.0288 & 0.0250 & 1.1526 & 0.2501 \\
D(ECI(-3)) & -0.0023 & 0.0210 & -0.1110 & 0.9117
\end{tabular}




\begin{tabular}{ccccc} 
C & $0.1910 * * *$ & 0.0645 & 2.9622 & 0.0033 \\
@ TREND & $0.0075 * *$ & 0.0030 & 2.4941 & 0.0133 \\
\hline Mean dependent VAR & 0.015537 & S.D. dependent VAR & 0.027652 \\
S.E. of regression & 0.014014 & Akaike info criterion & -4.53994 \\
Sum squared residuals & 0.050666 & Schwarz criterion & -1.6795 \\
Log likelihood & 2017.898 & Hannan-Quinn criteria. & -3.43392 \\
\hline
\end{tabular}

Notes: The dependent variable: D (LN(Y/L)). The model lag selection method is the Akaike Information Criteria (AIC). Dummy variables for the period fixed-effect and the country fixed-effect are also used in the estimations.

Table 3

Results of the Panel Quantile Regression (PQR) Estimations

\begin{tabular}{|c|c|c|}
\hline & Estimate & Bootstrapped Standard Errors \\
\hline \multicolumn{3}{|l|}{$\tau=10$ th } \\
\hline (Intercept) & $9.6510 * * *$ & 0.0923 \\
\hline$(\mathrm{ECI})$ & $0.0919 * * *$ & 0.0157 \\
\hline $\ln (\mathrm{RE})$ & $0.0190 * * *$ & 0.0065 \\
\hline $\ln (\mathrm{NRE})$ & $0.1963 * * *$ & 0.0097 \\
\hline \multicolumn{3}{|l|}{$\tau=25$ th } \\
\hline (Intercept) & $9.7539 * * *$ & 0.0669 \\
\hline$(\mathrm{ECI})$ & $0.0971 * * *$ & 0.0085 \\
\hline $\ln (\mathrm{RE})$ & $0.0210 * * *$ & 0.0052 \\
\hline $\ln (\mathrm{NRE})$ & $0.1844 * * *$ & 0.0063 \\
\hline \multicolumn{3}{|l|}{$\tau=50$ th } \\
\hline (Intercept) & $9.8121 * * *$ & 0.0567 \\
\hline$(\mathrm{ECI})$ & $0.0974 * * *$ & 0.0082 \\
\hline $\ln (\mathrm{RE})$ & $0.0195 * * *$ & 0.0043 \\
\hline $\ln (\mathrm{NRE})$ & $0.1803 * * *$ & 0.0057 \\
\hline \multicolumn{3}{|l|}{$\tau=75$ th } \\
\hline (Intercept) & $9.8631 * * *$ & 0.0635 \\
\hline$(\mathrm{ECI})$ & $0.0978 * * *$ & 0.0092 \\
\hline
\end{tabular}




\begin{tabular}{ccc}
$\ln (\mathrm{RE})$ & $0.0203 * * *$ & 0.0045 \\
$\ln (\mathrm{NRE})$ & $0.1757 * * *$ & 0.0059 \\
\hline$\tau=90 \mathrm{th}$ & & \\
\hline (Intercept) & $9.8247 * * *$ & 0.1099 \\
$(\mathrm{ECI})$ & $0.1218 * * *$ & 0.0163 \\
$\ln (\mathrm{RE})$ & $0.0162 * *$ & 0.0079 \\
$\ln (\mathrm{NRE})$ & $0.1805 * * *$ & 0.0099 \\
\hline
\end{tabular}

Notes: The bootstrapped standard errors with 2000 replications are reported. ${ }^{* * *} \mathrm{p}<0.01$ and $* *$ $\mathrm{p}<0.05$. The OLS standard errors are robust. The number of observations is 685 .

Appendix Table I

Descriptive Summary Statistics in 29 OECD Countries, 1990-2013 (685 Observations)

\begin{tabular}{|c|c|c|c|c|c|c|}
\hline Variable & Unit & Data Source & Mean & Standard Deviation & Skewness & Kurtosis \\
\hline Real per Capita GDP per engaged labor employment & Logarithmic Form & World Bank, WDI & 10.83 & 0.577 & -0.896 & 2.805 \\
\hline Total Renewable Energy Consumption & Million Tonnes Oil Equivalent & British Petroleum (BP) & 2.297 & 5.523 & 5.253 & 38.67 \\
\hline Total Non-renewable Energy Consumption & Million Tonnes Oil Equivalent & British Petroleum (BP) & 175.3 & 398.7 & 4.508 & 23.11 \\
\hline Economic Complexity Indicator & Index & Hausmann et al. (2011) & 1.254 & 0.678 & -0.401 & 2.475 \\
\hline
\end{tabular}

Appendix Figure I

Graphs for Output per Worker, Economic Complexity and Renewable and Non-renewable Energy Consumption 

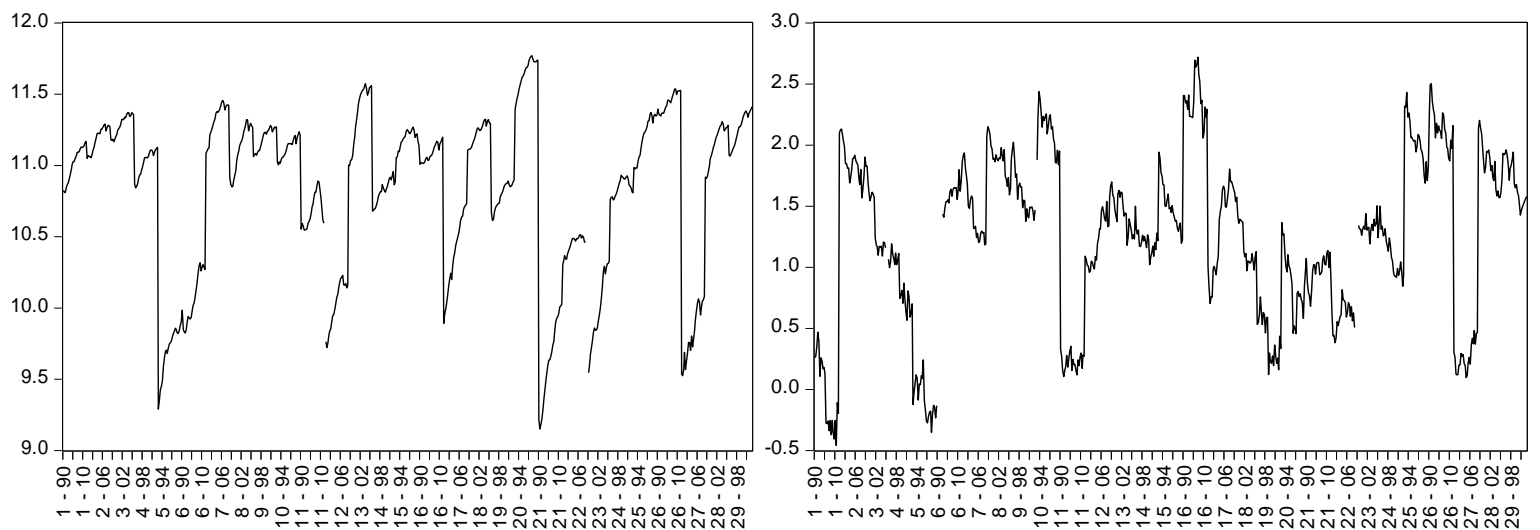

RENEW_ENECON

NONRENEW_ENECON
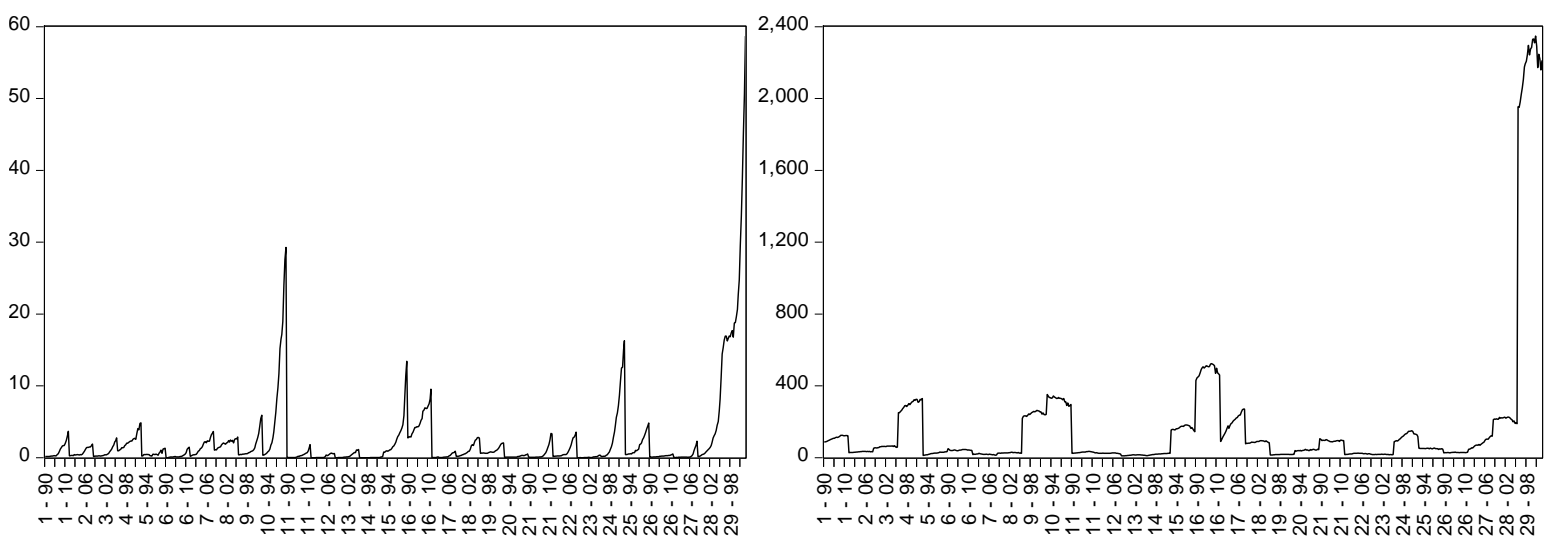